\title{
CARDIOVASCULAR MEDICINE
}

\section{Treatment of chronic heart failure with $\beta$ adrenergic blockade beyond controlled clinical trials: the BRING-UP experience}

\author{
A P Maggioni, G Sinagra, C Opasich, E Geraci, M Gorini, E Gronda, D Lucci, \\ G Tognoni, E Balli, L Tavazzi, on behalf of BRING-UP Investigators*
}

Heart 2003;89:299-305

See end of article for authors' affiliations

Correspondence to: Dr Aldo P Maggioni, ANMCO Research Centre, Via La Marmora, 34-50121 Florence, Italy; maggioni@anmco.it

* See the appendix for a complete list of participating centres and investigators

Accepted 20 November 2002

\begin{abstract}
Background: Several large controlled trials have shown that $\beta$ blockers given to patients with heart failure (New York Heart Association functional class II-IV) reduce morbidity and mortality. Despite these impressive results, implementing the use of $\beta$ blockade in clinical practice appears slow and difficult. The BRING-UP study was designed to tackle this problem.

Objectives: To accelerate the adoption of $\beta$ blockade in clinical practice; to provide an epidemiological estimate of the proportion of patients with heart failure suitable for this treatment in general cardiology care; and to assess effectiveness of these drugs outside the setting of clinical trials.

Methods: The design of the study and recommendations derived from available evidence on the use of $\beta$ blockers were discussed with cardiologists during regional meetings. All consecutive heart failure patients in a one month period, whether treated or not with $\beta$ blockers, were eligible for the study. In each patient, the decision to prescribe a $\beta$ blocker was a free choice for the participating physicians. All centres were provided with carvedilol, metoprolol, and bisoprolol at appropriate doses; the choice of the drug and dosage was left to the responsible clinician. All patients were followed for one year. Results: 197 cardiological centres enrolled 3091 patients, $24.9 \%$ of whom were already on $\beta$ blocker treatment at baseline. $\beta$ Blockers were newly prescribed in $32.7 \%$ of cases, more often in younger and less severely ill patients. The mean daily dose of the drugs used at one year corresponded to about $70 \%$ of the maximum dose used in clinical trials. Starting treatment with $\beta$ blockers did not affect the prescription or dosage of other recommended drugs. The overall rate of $\beta$ blocker treatment increased over the year of the study from $24.9 \%$ to $49.7 \%$. During the 12 month period, 351 deaths occurred $(11.8 \%)$. In multivariate analysis, the use of $\beta$ blockers was independently associated with a better prognosis, with a relative risk of 0.60 and a lower incidence of hospital admissions for worsening heart failure.

Conclusions: The implementation of $\beta$ blockers in clinical practice is feasible and could be accelerated. These drugs are associated with a lower mortality and reduced hospital admission rates, not only in clinical trials but also in the normal clinical setting.
\end{abstract}

n recent years, several large randomised trials have shown that the use of $\beta$ blockers in patients with congestive heart failure in New York Heart Association (NYHA) functional class II-IV is associated with a consistent, highly significant reduction in morbidity and mortality. ${ }^{1-4}$ Despite these impressive results, and the increasing availability of these drugs in appropriate formulations, implementation of the use of $\beta$ blockade in clinical practice has been disappointingly slow. ${ }^{56}$ This in part reflects a widespread mistrust of the use of $\beta$ blockers in congestive heart failure, probably because in the past these drugs have been specifically contraindicated in this clinical condition. Moreover, the possible initial impairment of cardiac performance, even if transient and followed by an improvement a few months later ${ }^{78}$ is not readily accepted by some physicians, who therefore regard this treatment as difficult to initiate and titrate. These hurdles, which are specific to chronic heart failure, need to be placed in the more general framework of the worldwide underuse of $\beta$ blockers for other cardiovascular diseases, such as acute myocardial infarction and the secondary prevention of coronary artery disease..$^{10}$

Overall, this use of $\beta$ blockers represents a model for the difficult translation of the results of randomised controlled trials into clinical practice, which is further complicated by the notable differences between the populations of patients enrolled in clinical trials and those commonly encountered in routine clinical practice. ${ }^{11}{ }^{12}$
We report here the results of a project started quite early in the era of $\beta$ blockade in heart failure. Its aim was to accelerate the adoption of $\beta$ blockade in clinical practice by cardiologists working for the Italian National Health Service.

While registration processes were taking place in various countries for this new indication, recommendations by scientific societies ${ }^{13}{ }^{14}$ were used as the starting point for implementing the use of $\beta$ blockers in a countrywide network of cardiology centres, most of which were already involved in an epidemiological study of patients with heart failure. ${ }^{15}$

The explicit aims of the study were as follows:

- to accelerate by guidance the use of $\beta$ blockade in outpatients with heart failure

- to provide an epidemiological estimate of the proportion of patients with heart failure who are candidates for $\beta$ blockade in general cardiology care

- to assess the degree of reproducibility of the inclusionexclusion criteria, dosing strategies, and tolerability observed in the selected populations enrolled in trials

- to assess the effectiveness of these drugs outside the scenario of clinical trials.

\section{METHODS}

The strategy adopted for implementing the BRING-UP study ( $\beta$ blockers in patients with congestive heart failure: guided 
Table 1 Summary of the recommendations for $\beta$ blocker use in patients with heart failure at the start of the study (1998)

\section{Indications}

Patients with symptomatic heart failure from any cause, with

depressed left ventricular function (ejection fraction $\leqslant 40 \%$ ), in NYHA

class II-III, clinically stable, already on treatment with ACE inhibitor, diuretic, and digitalis

Patients more likely to benefit are those with:

- History of hypertension

- Heart rate $>90$ beats/min

Patients less likely to benefit are those with:

- Severe biventricular dysfunction

- Systolic blood pressure $<100 \mathrm{~mm} \mathrm{Hg}$

- Heart rate $<60$ beats/min

\section{Uncertain indications}

Elderly patients ( $>75$ years)

NYHA class IV

Asymptomatic left ventricular dysfunction

Heart failure caused by valvar disease or diastolic dysfunction

Comorbidities (diabetes, mild to moderate obstructive pulmonary disease, renal failure, peripheral vascular disease)

\section{Contraindications}

Severe chronic obstructive pulmonary disease

First degree $\mathrm{AV}$ block ( $\mathrm{PQ}>0.28$ seconds) and second degree $\mathrm{AV}$

block (Mobitz 2 or advanced)

Heart rate $<50$ beats $/ \mathrm{min}$

Systolic blood pressure $<90 \mathrm{~mm} \mathrm{Hg}$

$\mathrm{ACE}$, angiotensin converting enzyme; $\mathrm{AV}$, atrioventricular; NYHA New York Heart Association.

use in clinical practice) started with the development and distribution to all Italian cardiologists of the recommendations derived from the available clinical evidence on the proper use of these drugs (table 1). Regional meetings involving more than 200 participating centres were organised to discuss the design of the study and the use of $\beta$ blockers in patients with congestive heart failure. All consecutive patients with heart failure, whether or not they were currently treated with $\beta$ blockers, were eligible for the study. For each patient entering the registry, the decision to adopt a therapeutic strategy that included $\beta$ blockers was a free choice of the individual physician involved, but the reasons for the physician's choice had to be documented in the ad hoc section of the study record form. No per patient fee was provided to the investigators or to the hospitals.

All participating centres were provided with carvedilol, metoprolol, and bisoprolol at appropriate doses in order to initiate their use and titrate their dose according to a schedule that reproduced as far as possible the strategies shown to be effective and safe in randomised clinical trials. The choice of the individual drug was left to the responsible clinician. The target doses, to be reached in approximately seven weeks, were: metoprolol tartrate $50 \mathrm{mg}$ three times daily, carvedilol $50 \mathrm{mg}$ twice daily, or bisoprolol $10 \mathrm{mg}$ once daily. Trained personnel from 10 leading cardiology centres served as a help line during the titration phase and beyond. At the time when the study was in the planning stage, $\beta$ blockers were not registered for heart failure treatment in Italy, so formal authorisation was obtained from the national regulatory authority to carry out a study that could be classified as a mixture of a phase IV trial and an outcomes research protocol.

After these preliminary phases, all patients with congestive heart failure seen over one month (from 19 January to 18 February 1998) were enrolled in the study and followed up for one year. The frequency of follow up visits was dependent on whether or not $\beta$ blocker treatment was initiated, as follows. All patients who were started on $\beta$ blockers at study entry or during the follow up period were seen on several occasions during the titration phase and at one and three months after starting the treatment; thereafter, all these patients-as well as those not treated with $\beta$ blockers-had clinical follow up appointments at six and 12 months, and information on their clinical status and hospital admissions was collected. All deaths were documented, and the cause of death was determined by the responsible clinician from an evaluation of the clinical records in patients who died in hospital, or by collecting information from relatives and from the death certificate when the death occurred outside hospital.

\section{Statistical analysis}

The stratification of the study cohort was predefined as follows: (1) patients already treated with $\beta$ blockers at entry; (2) patients newly allocated to $\beta$ blockers; and (3) patients not considered for $\beta$ blockade.

Clinical and demographic characteristics, incidence of hospital admissions, total mortality, and sudden mortality were compared by $\chi^{2}$ tests. Differences in continuous variables were tested by one way analysis of variance.

Multivariate analyses were used to evaluate the independent contribution of the different variables on the following end points: initiation of $\beta$ blocker treatment (logistic regression models); permanent discontinuation of $\beta$ blockers once started (logistic regression models); and total mortality during the one year follow up (Cox model).

Collection, quality control, and analyses of data were undertaken at the research centre of the Italian Association of Hospital Cardiologists (ANMCO) in Florence (Italy).

\section{RESULTS}

\section{Patient enrolment}

During one month, 197 centres (about 32\% of the existing cardiology centres throughout Italy) enrolled 3091 patients. The geographical distribution and the technical and organisational complexity of these centres (that is, their angiographic facilities, cardiac surgery facilities, etc) are representative the current management of patients with congestive heart failure in Italian cardiology units. Figure 1 shows the distribution of patients who were already on treatment $(24.9 \%)$, those who started treatment either at the beginning of the study or during follow up (32.7\%), and those who were not treated with $\beta$ blockers during the study (42.4\%).

\section{Predictors of the use of $\beta$ blockers}

The mean (SD) age of the patients enrolled in the study was 64 (12) years, with women accounting for $27.3 \%$ of the cases. Half of the patients (52.5\%) were in NYHA functional class II. An ejection fraction measurement was available in $95.4 \%$ of the cases. Table 2 lists the main clinical and demographic variables in the three groups of patients. There were significant differences in the distribution of the aetiology of heart failure among the three groups. $\beta$ Blockers were prescribed more often in patients with dilated or hypertensive heart failure. Furthermore, patients treated with or starting on $\beta$ blockers were usually younger and less often had signs or symptoms of severe heart failure than patients for whom treatment was not started. In the latter group, reasons why treatment was not given at the enrolment visit were as follows: contraindications to $\beta$ blockers $(n=540 \quad(37.1 \%))$; uncertain indications $(\mathrm{n}=392(26.9 \%))$; logistic reasons $(\mathrm{n}=149(10.2 \%))$; other reasons $(n=470(32.3 \%))$. Patients could have more than one reason for treatment exclusion.

Among the 540 patients considered to have contraindications to $\beta$ blocker treatment, severe chronic obstructive pulmonary disease was the cause in the majority of cases (59\%), followed by severe peripheral vascular disease (14\%), a systolic blood pressure $\leqslant 90 \mathrm{~mm} \mathrm{Hg}(9 \%)$, concomitant intravenous treatment with inotropes $(7 \%)$, a heart rate $<50$ beats/min $(7 \%)$, first degree atrioventricular block with a PQ interval $>0.28 \mathrm{~s}(6 \%)$, and advanced atrioventricular block $(4 \%)$. 


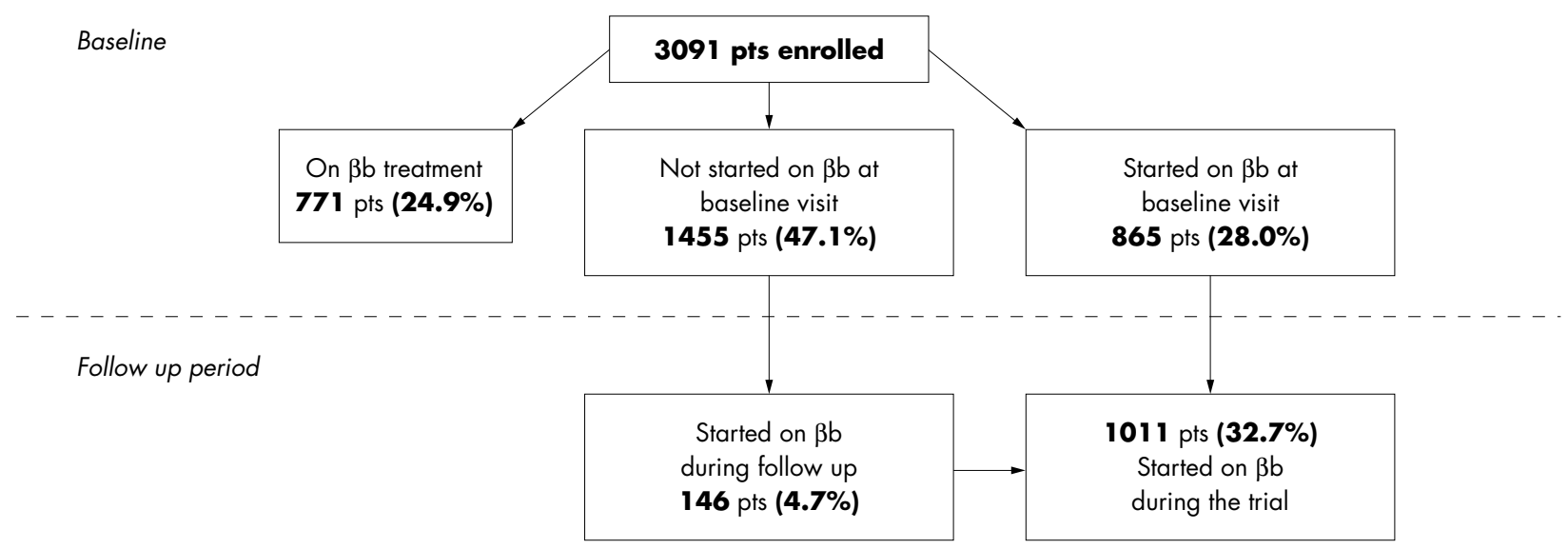

1 year follow up

2987 pts with data available

104 pts (3.4\%)

lost to follow up

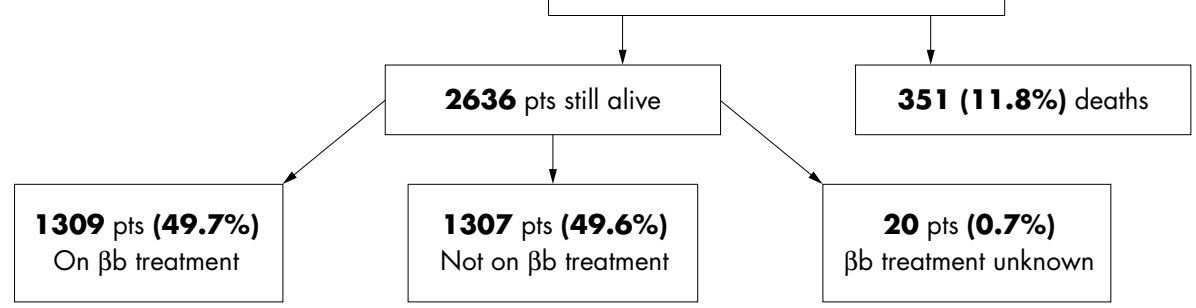

Figure 1 Flow chart of the study. $\beta b, \beta$ blocker.

Among the 392 patients considered to have uncertain indications, age over 75 years was the cause in the majority of cases $(59 \%)$, followed by asymptomatic left ventricular dysfunction (31\%), and NYHA functional class IV (14\%).

To assess the independent influence of baseline clinical variables on whether or not $\beta$ blocker treatment was started, a multivariate analysis was undertaken. This showed that lower age, lower NYHA class, higher systolic blood pressure, and a higher heart rate were all independently associated with the use of $\beta$ blockers (table 3 ), whereas hypertension, diabetes, left ventricular ejection fraction $(<30 \% v \geqslant 30 \%)$, atrial fibrillation, aetiology (ischaemic $v$ not ischaemic), and sex were not independently related to the use of these drugs. Patients in whom an ejection fraction measurement was not available were significantly less likely to be treated with $\beta$ blockers.

\section{Drug management}

Of the patients already on $\beta$ blocker treatment at study entry, $73 \%$ were treated with carvedilol, $18 \%$ with metoprolol, and
$1 \%$ with bisoprolol, while $8 \%$ were using a variety of other $\beta$ blockers; of the patients who started treatment at study entry, carvedilol was chosen in $85 \%$, metoprolol in $13 \%$, and bisoprolol in $2 \%$.

The mean daily dosage of carvedilol reached a plateau at three months, with large interindividual variation (mean (SD) daily dosage, 30.7 (21.4) mg, median $25 \mathrm{mg}$ ), and was maintained at a similar level at one year $(34.0$ (23.0) $\mathrm{mg}$, median $25 \mathrm{mg}$ ). The mean daily dose of carvedilol at one year corresponded to $68 \%$ of the maximum dose ( $50 \mathrm{mg}$ daily) suggested by the most relevant clinical trial testing this drug. ${ }^{1}$ An equivalent dosage profile was observed with metoprolol and bisoprolol.

Although the use of other cardiovascular drugs was significantly different in the three groups (table 4), starting treatment with $\beta$ blockers did not affect the prescription or dosage of other recommended drugs overall. For example, in patients started on $\beta$ blockers, the mean dose of enalaprilwhich was the most prescribed angiotensin converting

Table 2 Clinical and demographic characteristics

\begin{tabular}{lllll}
\hline Characteristic & $\begin{array}{l}\text { On } \beta \text { blockers } \\
(\mathbf{n}=771)\end{array}$ & $\begin{array}{l}\beta \text { Blockers started } \\
(\mathbf{n}=865)\end{array}$ & $\begin{array}{l}\text { No } \beta \text { blockers } \\
(\mathbf{n}=1455)\end{array}$ & p Value \\
\hline Age $\geqslant 70$ years & 24 & 25 & 43 & 0.001 \\
NYHA class III-IV & 26 & 29 & 42 & 0.001 \\
Pulmonary rales & 10 & 20 & 26 & 0.001 \\
Peripheral oedema & 12 & 13 & 21 & 0.001 \\
Atrial fibrillation & 14 & 17 & 21 & 0.001 \\
EF not available & 5 & 3 & 6 & 0.008 \\
EF <30\% & 30 & 30 & 35 & 0.017 \\
& & & & \\
Aetiology & 38 & 39 & 42 & 0.001 \\
Ischaemic & 38 & 34 & 28 & \\
Dilated & 13 & 16 & 14 & \\
Hypertensive & 11 & 11 & 16 & \\
Other & & & \\
\hline
\end{tabular}

Values are percentages.

$E F$, ejection fraction; NYHA, New York Heart Association. 
Table 3 Independent predictors of use of $\beta$ blockers

\begin{tabular}{llll}
\hline Variable & OR & $95 \% \mathrm{Cl}$ & $\mathrm{p} \mathrm{Value}$ \\
\hline Age (as a continuous variable) & 0.97 & 0.96 to 0.97 & 0.0001 \\
NYHA class (III-IV v I-II) & 0.62 & 0.51 to 0.75 & 0.0001 \\
Systolic blood pressure (as a continuous variable) & 1.02 & 1.01 to 1.02 & 0.0001 \\
Heart rate (as a continuous variable) & 1.01 & 1.01 to 1.02 & 0.0001 \\
Ejection fraction (not available v available) & 0.46 & 0.28 to 0.76 & 0.0022 \\
\hline Cl, confidence interval; NYHA, New York Heart Association; OR, odds ratio.
\end{tabular}

\begin{tabular}{lllll} 
Table 4 & Use of concomitant cardiovascular drugs & & \\
\hline & $\begin{array}{l}\text { On } \beta \text { blockers } \\
(\mathrm{n}=771)\end{array}$ & $\begin{array}{l}\beta \text { Blockers started } \\
(\mathrm{n}=865)\end{array}$ & $\begin{array}{l}\text { No } \beta \text { blockers } \\
(\mathrm{n}=1455)\end{array}$ & p Value \\
\hline ACE inhibitors & 85 & 85 & 86 & NS \\
Diuretics & 85 & 86 & 92 & 0.001 \\
Digitalis & 57 & 65 & 67 & 0.001 \\
Amiodarone & 12 & 14 & 24 & 0.001 \\
Oral anticoagulants & 29 & 24 & 28 & 0.049 \\
Nitrates & 37 & 40 & 48 & 0.001 \\
\hline Values are percentages. & & & \\
ACE, angiotensin converting enzyme. & & &
\end{tabular}

enzyme (ACE) inhibitor-was 19 (11) mg at baseline and 20 (11) mg after one year. Enalapril was also given at a similar mean dose in patients who were not started on $\beta$ blockers ( 16 (9) $\mathrm{mg}$ at baseline and 17 (9) $\mathrm{mg}$ after one year).

In patients started on $\beta$ blockers, permanent discontinuance decreased progressively with time. In the first month the withdrawal rate was $12.5 \%$, between $1-3$ months it was $4.0 \%$, between 3-6 months it was 3.1\%, and between 6-12 months it was $4.0 \%$. Overall, $23.6 \%$ of patients stopped $\beta$ blocker treatment during follow up. The leading reasons were worsening congestive heart failure (8.4\%), hypotension $(3.1 \%)$, patient preference $(2.9 \%)$, worsening of chronic obstructive

Table 5 Independent predictors of permanent discontinuation of $\beta$ blockers

\begin{tabular}{llll}
\hline Variable & OR & $95 \% \mathrm{Cl}$ & $\mathrm{p}$ Value \\
\hline Age (as a continuous variable) & 1.02 & 1.01 to 1.04 & 0.0331 \\
NYHA class (III-IV $v$ I-II) & 1.50 & 1.05 to 2.13 & 0.0256 \\
$\begin{array}{l}\text { Systolic blood pressure } \\
\text { (as a continuous variable) }\end{array}$ & 0.98 & 0.97 to 0.99 & 0.0169 \\
Aetiology (ischaemic $v$ not ischaemic) & 1.45 & 1.02 to 2.08 & 0.0408 \\
\hline
\end{tabular}

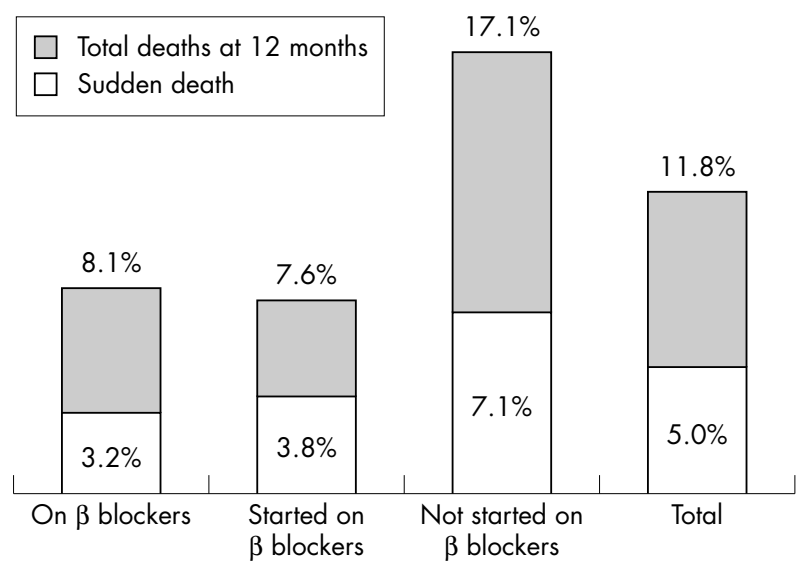

Figure 2 Total mortality and sudden deaths by 12 months, broken down by $\beta$ blocker treatment. pulmonary disease (1.9\%), and bradycardia or atrioventricular block ( $1.8 \%)$.

In multivariate analysis, older age, lower systolic blood pressure, higher NYHA class, and an ischaemic cause for congestive heart failure were independently predictive of the discontinuation of $\beta$ blockers (table 5).

\section{Morbidity and mortality during follow up}

Overall, during the 12 month follow up period, 351 deaths (11.8\%) occurred among the 2987 patients for whom follow up data were available. Figure 2 shows the incidence of total and sudden death in the three groups and overall. Between $39-50 \%$ of overall deaths were sudden, with no significant differences among the three groups.

Independent predictors of total one year mortality are listed in table 6. As expected, higher NYHA class, lower left ventricular ejection fraction, age, and higher heart rate were all independently related to total mortality. The use of $\beta$ blockers was independently associated with a better prognosis, with a relative risk of 0.60 corresponding to a risk reduction of $40 \%$.

The incidence of hospital admissions for worsening heart failure was also significantly different among the three groups of patients (fig 3). During the first six months, patients in whom $\beta$ blockers were started showed a hospital admission rate that was similar to that of patients never started on $\beta$ blockers, and twice that in patients already on treatment. From 6-12 months, the hospital admission rate in patients started on $\beta$ blockers was similar to that observed in patients

Table 6 Independent predictors of one year overall mortality

\begin{tabular}{|c|c|c|c|}
\hline Variable & RR & $95 \% \mathrm{Cl}$ & $\mathrm{p}$ Value \\
\hline NYHA class (III-IV $v$ I-II) & 2.04 & 1.62 to 2.57 & 0.0001 \\
\hline Ejection fraction $(<30 \% v \geqslant 30 \%)$ & 1.65 & 1.30 to 2.08 & 0.0001 \\
\hline Age (as a continuous variable) & 1.03 & 1.02 to 1.04 & 0.0001 \\
\hline Heart rate (as a continuous variable) & 1.02 & 1.01 to 1.02 & 0.0001 \\
\hline $\begin{array}{l}\text { Systolic blood pressure } \\
\text { (as a continuous variable) }\end{array}$ & 0.98 & 0.97 to 0.98 & 0.0001 \\
\hline Use of $\beta$ blockers (started $v$ not treated) & 0.60 & 0.45 to 0.80 & 0.0003 \\
\hline $\begin{array}{l}\text { Use of } \beta \text { blockers (on treatment } v \text { not } \\
\text { treated) }\end{array}$ & 0.74 & 0.55 to 0.99 & 0.0446 \\
\hline
\end{tabular}



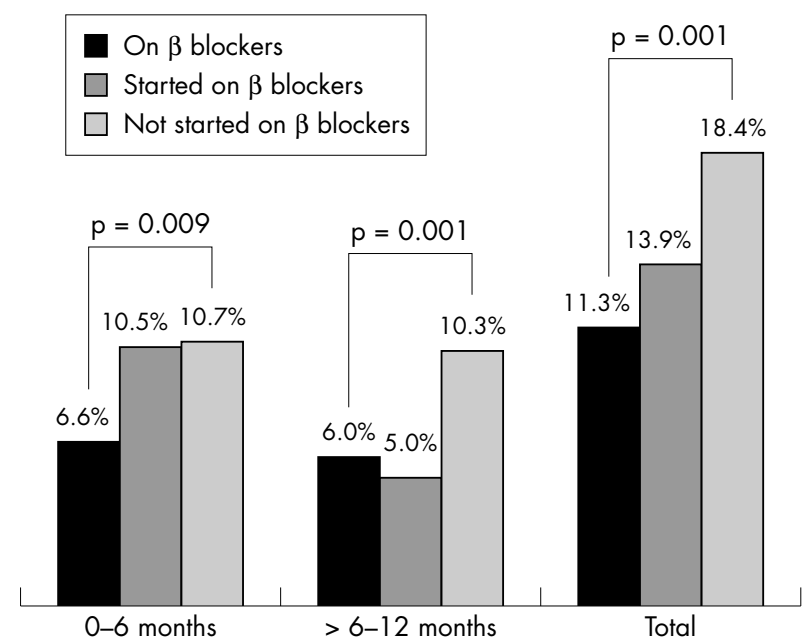

Figure 3 Time course of hospital admissions for worsening heart failure, broken down by $\beta$ blocker treatment.

already on treatment when the study was started, while no changes were noted in patients not started on $\beta$ blockers.

\section{DISCUSSION}

We will consider the results of the BRING-UP study from two complementary points of view: the actual findings on the quantitative and qualitative profile of the use of $\beta$ blockade in heart failure in routine clinical practice; and the value of the BRING-UP strategy in terms of its educational role in promoting the incorporation of trial results into general practice.

\section{$\beta$ Blocker use in heart failure in routine clinical practice} $\beta$ Blockade was adopted as part of heart failure treatment in up to $37 \%$ of the patients who were not already on $\beta$ blocker treatment at the entry visit. Overall, the participating cardiologists decided to maintain, or prescribe as a new treatment, a $\beta$ blocker agent in about 53\% of the heart failure patients consecutively seen in the one month enrolment period of the study.

Chronic obstructive pulmonary disease was the most common contraindication to $\beta$ blocker use. The high prevalence of this contraindication suggests that cardiologists perceived all manifestations of chronic obstructive pulmonary disease as risk factors for worsening pulmonary function after starting $\beta$ blockade. However, in some of these patients, the potential benefit of using $\beta$ blockers may outweigh the risk. Only asthma and reversible airways obstruction should be considered as contraindications to the use of any $\beta$ adrenergic inhibitor.

Besides specific contraindications, the major reasons for non-prescription of $\beta$ blockers were advanced age, NYHA class IV, and asymptomatic left ventricular dysfunction. It is worth noting, however, that the BRING-UP study was conducted when the COPERNICUS and CAPRICORN trial results were not yet available. ${ }^{16}{ }^{17}$ To improve the prescription of $\beta$ blockers in this subgroup of patients, for whom evidence of benefit from $\beta$ blockers is now available, the BRING-UP 2 study has been designed and is presently underway.

Nearly $80 \%$ of the patients of this study were treated with carvedilol. The selection of this drug was probably related to the fact that, at the time of the patients' enrolment, the results of the US carvedilol programme were available, while those of CIBIS II (bisoprolol) and MERIT heart failure (metoprolol) trials $^{23}$ were not.

$\beta$ Blockade was well tolerated, with $76 \%$ of patients remaining on treatment after one year and the majority of permanent discontinuations occurring during the first month.
This withdrawal rate is close to the rates observed in heart failure patients allocated to placebo in randomised trials. ${ }^{1-3}$

BRING-UP shows that $\beta$ blocker treatment is not harmful; on the contrary, it is associated with a reduction in total mortality which, after correcting for the available confounding variables, is strikingly similar to that observed in randomised clinical trials ( $40 \%$ reduction in overall mortality). ${ }^{2-4}$ This is in line with the results of recent studies comparing the findings obtained in observational and randomised trials, ${ }^{18}{ }^{19}$ and shows that well designed observational studies can give results similar to those obtained in randomised trials. Randomised controlled trials remain, obviously, the only proper tool to evaluate the efficacy and safety of new treatments. ${ }^{20}$ Observational studies should not be considered as alternatives, but as important adjuncts, complementary to randomised studies. Their main purpose is to verify whether the new treatment is used, if it is used properly, and whether its efficacy under controlled conditions in tertiary care centres translates into effectiveness in routine practice.

One relevant issue with respect to the correct use of drugs is the dosage. In our study clinicians tended to stop up titration of $\beta$ blockers at a lower dose than recommended on the basis of the trial results. ${ }^{21}{ }^{22}$ This suggests that the dose issue should be a focus in future educational initiatives. However, it is worth remembering that the relatively low rate of side effects observed in the $\beta$ blocker treatment group in this study was associated with a dose of $\beta$ blockers considered low as judged by the target doses suggested by current guidelines. This observation is consistent with the recent findings that low dose $\beta$ blocker treatment can reduce the rate of hospital admissions for heart failure and improve survival in elderly patients after myocardial infarction, ${ }^{23}$ and that carvedilol has been shown to improve left ventricular function at relatively low doses. ${ }^{24}$

The administration of $\beta$ blockers was not associated with changes in the prescription rates or dosages of other drugs, including ACE inhibitors, indicating that the initiation of $\beta$ blockers does not deprive patients of other treatments that are shown to be effective.

A further interesting observation concerning the safety of the treatment was the hospital admission rate during follow up in patients started on the treatment during the study period: $10.5 \%$ were admitted during the first six months ( similar to the admission rate in more severely compromised patients not given $\beta$ blockers), while $5.2 \%$ were admitted during the second six month period (similar to the rate of patients already on treatment when the study was started). If these changes are not due to chance-which is possible but unlikely, given the stability of the hospital admission rates over time in the other two groups of patients-the obvious interpretation is that the beneficial effects of $\beta$ blockers can appear later after the onset of treatment. As BRING-UP was an open study, the alternative interpretation that physicians were more prone to admit their patients when symptoms occurred or worsened soon after starting $\beta$ blockade cannot be ruled out. Whatever the interpretation, this finding has to be considered in the cost-benefit analyses.

\section{The BRING-UP strategy for the incorporation of trial results into general practice}

Compared with published reports-which have documented with impressive consistency the effects of these agents and the corresponding prescribing behaviours ${ }^{25}{ }^{26}$ - the results of the BRING-UP study, with its large cohort of patients, show that the process of incorporating the results into normal clinical practice could well be accelerated and might proceed in parallel with confirmation of the early evidence and implementation of the registration processes.

These results are relevant because of the perception that congestive heart failure is a contraindication to $\beta$ blocker use, 
and because of the difficulties in managing these drugs in the early titration phase. The attitude of working collaboratively, so that there is a combination of total clinical freedom and the ability to consult if and when necessary, could be seen as a blend of continuity and adaptation to the trial setting and rules. Informed subjective medical decisions, with exclusion criteria limited to formal contraindications, were accompanied by a very low level of monitoring in our study, which mimics the conditions obtaining in good clinical practice, where consultation with peers in cases of uncertainty should be the norm.

It is clear that all the classical limitations of observational studies ${ }^{20}$ could be applied to the BRING-UP study, and that its local nature could be seen as a major limitation to its applicability in an international setting. Nevertheless such caveats should not undermine the fact that strategies involving transferability and effectiveness must be locally planned, as results must be pursued and measured in specific societal frameworks and health systems.

In the case of BRING-UP, the main sponsor and coordinating body is a scientific association which has been developing a culture of cooperative research as a critical component of the professional identity of the cardiology community and of its individual members. ${ }^{27}{ }^{28}$ External financial support was required only for the coordination activities. More generally, the introduction of truly innovative knowledge and behaviour into daily care is better seen as a research process in itself, because the transfer from efficacy to effectiveness cannot and should not be an exercise in obedience and reproduction. Not only are the patients and the clinical contexts much more heterogeneous than they are in clinical trials, but the incorporation of new knowledge on top of existing knowledge is also largely dependent on the unpredictable variability of many physicians, for whom the trade off between clinical freedom and evidence remains an interesting exercise to be validated on each new occasion. Periodic descriptive surveys of practice patterns aiming at measuring the gap between research results and clinical attitudes, or the impact of educational campaigns, should be considered a second choice compared with active research projects targeted towards improving medical practice by providing a better understanding of physicians' behaviour and by measuring outcomes with end points that are an epidemiological translation of the outcomes of controlled trials.

Along with the important ad hoc initiatives launched mainly in the USA ${ }^{29}$ and the $\mathrm{UK}^{30}$ to promote evidence based practice, scientific societies should be in the forefront of the methodological development and concrete testing of research models in this critical area of medicine. The potential implications of such strategies could be considered either in terms of public health or of the cost-benefit profile of medicine, because the investigator networks overlap the user community.

\section{ACKNOWLEDGEMENTS}

The study was supported in part by Roche Spa Italy. Study drugs were provided by Roche Spa Italy, Novartis, and Bracco.

\section{APPENDIX}

\section{Steering committee}

Luigi Tavazzi (Chairman), Alessandro Boccanelli, Fulvio Camerini, Antonello Gavazzi, Edoardo Gronda, Enrico Geraci, Aldo P Maggioni, Claudio Rapezzi, Gianfranco Sinagra, Gianni Tognoni, Lorella Colombi

\section{Executive committee}

Aldo P Maggioni, Marino Scherillo, Luigi Tavazzi

\section{Data management, revision and analysis}

Enrico Balli, Barbara Bartolomei, Gianna Fabbri, Marco Gorini, Donata Lucci
Participating centres and investigators by geographical region

Piemonte e Valle D'Aosta: Acqui Terme (P L Roncarolo, R Caneparo); Aosta, (M De Marchi, G Begliuomini); Borgomanero (M Zanetta, M Bielli); Casale Monferrato (M Ivaldi, M T Curti); Cuneo (E Uslenghi, U Milanese); Domodossola (G Tirella, G Folini); Ivrea (P Idone, G Bergandi); Orbassano (P Greco Lucchina, R Pozzi); Rivoli (M R Conte, I Contrafatto); Savigliano (M Di Leo, G Baralis); Torino, CTO (E Commodo, L Spadaccini); Torino, Osp Maria Vittoria (R Trinchero, G Gaschino); Torino, Osp Martini (G Brocchi, R Crivello); Torino, Osp Molinette (E Rosettani, M Bobbio); Veruno (P Giannuzzi, E Bosimini); Lombardia: Bergamo (M De Tommasi, F D'Adda); Brescia (C Rusconi, P Faggiano); Busto Arsizio (E Cecchetti, A Medici); Cassano D'Adda (G Gibelli, G Castiglioni); Chiari (C Bellet, A Turelli); Codogno (C Marinoni, A Marras); Como (M Santarone, G Foglia Manzillo); Crema (G Zavatteri, D Tovena); Desio (M De Martini, S Gramenzi); Erba (G Maggi, C Falcone); Gallarate (R Canziani, F Galdangelo); Garbagnate Milanese (A Grieco, E Cazzani); Giussano (C Moja, D Cuzzucrea); Gussago (A Giordano, S Scalvini); Lecco (M Bossi, V Locatelli); Legnano (S De Servi, F Passoni); Mantova (G Guerra, M R Ferrari); Milano, Fond Don Gnocchi (S Pirelli, E Gara); Milano, Istituti Clinici Perfezionamento ( Di Michele, M Stefanelli); Milano, Istituto Nazionale Tumori (S Biasi, C Materazzo); Milano, Osp dei Bambini ( $\mathrm{T}$ Pupilella); Milano, Osp Niguarda (A Pezzano, M Mangiavacchi); Montescano (F Cobelli, S Capomolla); Monza (F Valagussa, A Vincenzi); Mozzo (M De Tommasi, D Mazzoleni, M Rondi); Pavia (L Tavazzi, A Giusti); San Giovanni Bianco (B Cavallini); Saronno (A Croce, D Nassiacos); Seriate (P Giani, T Nicoli); Sesto San Giovanni ( Melloni, G Signorelli); Sondalo (G Occhi, M G Rosella); Suzzara (C Calestani, M Giovannini); Tradate, Fond S Maugeri (R Tramarin, R Pedretti); Tradate, Osp di Circolo Galmarini (G Poggio, M Ravetta); Varese, Ospedale di Circolo (G Binaghi, F Morandi); Vigevano (S Nava, R Villani); Vizzolo Predabissi (G Colombo, E Planca); Voghera (C Pasotti, P Gandolfi); P A Trento: Arco (D Di Spazio, G Mirante Marini); Rovereto, Medicina (M Mattarei, C Pedrolli); Veneto: Belluno (G Catania, O Palatini); Mestre (F Bellavere, S Fattore); Mirano (P Pascotto, P Sarto); Montebelluna (R Buchberger, M G Stefanini); Padova (S Dalla Volta, G M Boffa); Portogruaro (R Cazzin, G Di Fonso); San Bonifacio (R Rossi, E Carbonieri); San Donà di Piave (L Milani, R Valle); Thiene (B Martini, G Basso); Treviso (P Stritoni, G Renosto); Friuli: Gemona del Friuli (S Baldissera, M A Iacono); Gorizia (A Fontanelli, G Giuliano); Monfalcone (T Morgera, E Barducci); Sacile (M Scarpa, U Grandis); Trieste (G Sinagra, A Di Lenarda); Liguria: Arenzano (R Griffo, A Camerini); Genova, Osp Galliera (C Vecchio, M Falcidieno); Rapallo (G Gigli, S Orlandi); Sarzana (G Filorizzo, D Bertoli); Emilia Romagna: Bentivoglio (G Di Pasquale, L G Pancaldi); Bologna, Osp Bellaria (G Pinelli, E Talamonti); Cesena (F Tartagni, A Tisselli); Correggio (S Signorelli, S Bendinelli, L Lusetti); Fidenza (L Andreoli, S Baccarini); Guastalla (G Bruno, D Tsialtas); Imola (I Gardi, Negroni); Mirandola (L Gibertoni, M Gavioli); Modena, Osp Sant'Aostino (G R Zennaro, F Melandri); Modena, Policlinico (M G Modena, F Cionini); Parma, Osp Stuard (G Valenti, M Tonelli, A Giordano); Parma, Osp Riuniti (F Naccarella, A Maurizio); Reggio Emilia (U Guiducci, S Roti); Rimini (F Rossi, P L Semprini); Scandiano (G Bellodi, M Zobbi, G P Gambarati); Toscana: Castelnuovo Garfagnana (D Bernardi, P R Mariani); Cortona (M Grazzini, F Cosmi); Empoli (A Bini, F Venturi); Firenze, Osp S M Nuova (F Marchi, G Zambaldi); Lucca (E Nannini, A Boni); Massa (V Bonatti, A Mariani); Orbetello (G Costanzi, V Campanella, C Zecchi); Pescia (W Vergoni, G Italiani); Pisa (A Biagini, M Baroni); Pistoia (F Del Citerna, A Giomi); Pontedera (G Squarcini, A M Paci); Portoferraio (G Micheli, G Giacomelli, A Iurato); Sansepolcro (R Tarducci, P Rossi); Viareggio (A Pesola, A Dalle Luche); Volterra (A M Ballestra, C Arlotta); Umbria: Amelia (P Cerruti, F Poti); Foligno (M Massi Benedetti, U Gasperini); Perugia, Monteluce (L Corea, G Alunni, E Bosi); Spoleto (N Miele, G Bardelli); Marche: Ancona, Osp Sestilli (E Paciaroni, L Quattrini); Ancona, Osp Lancisi, Medicina Sociale (R Mocchegiani); Ancona, Osp Lancisi, II Cardiologia (A Soro, G Cesari); Macerata (D Caporicci, A Mori); Senigallia (N Ciampani, Dorni); Lazio: Albano Laziale (G Ruggeri, P Midi, R Anastasi); Civitavecchia (M Di Gennaro, S Calcagno); Colleferro (M Mariani, M Pagliei); Gaeta (V Vozzolo, E Daniele); Roma, CTO (M Uguccioni, G Gattini); Roma, Osp Forlanini (A M Tamiz, F Pozzar, A Terranova); Roma, Osp FBF (G Angrisani, M Fioranelli); Roma, Osp Cristo Re (D Lombard, V Baldo); Roma, Osp San Camillo, II Div Cardiologia (E Giovannini, G Pulignano); Roma, Osp San Camillo, Servizio (G Cacciatore, M Menichelli); Roma, Osp S Filippo Neri (M Santini, G Ansalone); Roma, Osp S Giovanni (A Boccanelli, G Scaffidi); Roma, Osp San Pietro FBF (F Ferri, P L Delle Grotti); Roma, Osp S Spirito (V Ceci, N Aspromonte); Abruzzo: Chieti (C Di Iorio, L Cavasinni); Giulianova (P Di Sabatino, G Lombardi); 
Penne (A Vacri, A De Finis); Sulmona (F Pelini, B Di Marcantonio); Vasto (G Di Marco, M Colaneri); Campania: Avellino (D Rotiroti, G Rosato); Aversa (G De Marco, P Iodice); Bisaccia (S Frullone, G Macina); Caserta, Cardiologia ( $\mathrm{G}$ Corsini, A Malvezzi); Caserta, Cardiologia Riabilitativa (C Chieffo, A Palermo); Castellammare di Stabia (G Pepe, G De Caro); Cava dei Tirreni (R Della Monica); Marcianise (L Sabino, A Tartaglione); Napoli, Fondazione Pascale (A Basso, U Bianchi); Napoli, Osp Ascalesi (A Imperatore, F Scafuro); Napoli, Osp Cardarelli, Cardiologia (A Boccalatte, N Maurea); Napoli, Osp Cardarelli, Medicina d'Urgenza (L Mazzitelli, F Piantadosi); Napoli, Osp Loreto Mare (G Granato Corigliano, L Irace); Napoli, Osp Monaldi (N Mininni, S Siciliano); Nola (F Napolitano, P Provvisiero); Oliveto Citra (G D'Angelo, M R Di Muro); Polla (T Di Napoli, R Penna); Pollena Trocchia (L Filosa, C Nunziata); Pozzuoli (G Sibilio, N Moio); Scafati (A Pesce, S De Luca); Sorrento (S D'Amato, F Maresca); Torre Annunziata (F Di Palma, C Sestri); Torre del Greco (M Gaio, C Arrotino); Puglia: Andria (S Figliolia, R Musaico); Bari, Policlinico (I De Luca, E Fino); Bari, Osp San Paolo (G Franchini, M L Lenti); Bari, Osp di Venere (P Ginevrino, N D'Amato); Casarano (G Pettinati, G Storti); Castellana Grotte (D Mastrangelo, A Di Masi); Francavilla Fontana (V Cito, G Vecchio); Gagliano Del Capo (F Gianfreda, G Pisa); Gallipoli (C Schirinzi, F Mariello); Grottaglie (C Forleo, V Portulano); Lecce (F Bacca, F Magliari); Mesagne (V Santoro, E Angelini); Putignano (E Cristallo, G Cellamare); San Pietro Vernotico (L Vergallo, A Renna, S Pede); Scorrano (E De Lorenzi, O De Donno); Taranto (A Albano, A Peluso); Tricase (A Galati, R Mangia); Basilicata: Lagonegro (R Lauletta, L Oliveto); Policoro (B D'Alessandro, E De Nittis); Venosa (S Barbuzzi, V Capogrosso); Calabria: Castrovillari (C Calvelli, C Amenta); Cosenza (F Plastina, G Misuraca); Paola (P Bencardino, M Balsano); Polistena (R M Polimeni, F Catananti); Rogliano (F Russo, A Provenzano, M T Manes); Rossano (S Salituri); Trebisacce (L Donnangelo, G Meringolo); Sicilia: Alcamo (F Ippolito, M Benenati); Caltagirone (D Malfitano, A Ferrante); Canicattì (L Malluzzo, G Costanza); Catania, Osp Cannizzaro (V Carini, R Coco); Marsala (G Ingianni, C Attardo); Messina, Osp Piemonte (F Freni, G Di Tano); Palermo, Osp Civico (E D’Antonio, G Oliva); Palermo, Osp Ingrassia (G Barone, F Clemenza); Palermo, Villa Sofia (A Battaglia, F Ingrillì); Piazza Armerina (B Aloisi, M Farruggio); Ragusa (V Spadola, M L Guarrella); Sciacca (V Indelicato, M Bono); Siracusa (B Brancati, B Maltese); Trapani (G B Braschi, G Ledda); Sardegna: Cagliari, Osp Brotzu (A Sanna, M Porcu); Carbonia (R Aste, S Cherchi); Olbia (G Secchi, P Zappadu, S Casula); San Gavino Monreale (E Spiga, G Giardina); Tempio Pausania (L Addis, P Bellu, F Pala); Thiesi (F Masala, G Poddighe).

\section{Authors' affiliations}

A P Maggioni, M Gorini, D Lucci, ANMCO Research Centre, Florence, Italy

G Sinagra, Department of Cardiology, Maggiore Hospital, Trieste, Italy C Opasich, Department of Cardiology, Fondazione Salvatore Maugeri, Pavia, Italy

E Geraci, Department of Cardiology, Cervello Hospital, Palermo, Italy E Gronda, Department of Cardiology, Istituto Clinico Humanitas, Milan Italy

G Tognoni, Mario Negri Institute, Milan, Italy

E Balli, Department of Cardiology, Spedali Riuniti, Pistoia, Italy

L Tavazzi, Department of Cardiology, S Matteo Hospital, Pavia, Italy

\section{REFERENCES}

1 Packer M, Bristow MR, Cohn JN, et al. The effect of carvedilol on morbidity and mortality in patients with chronic heart failure. N Engl Med 1996;334:1349-55.

2 CIBIS-II Investigators and Committees. The cardiac insufficiency bisoprolol study II (CIBIS-II): a randomised trial. Lancet 1999;353:9-13.
3 MERIT-HF Study Group. Effects of metoprolol CR/XL in chronic heart failure: metoprolol CR/XL randomized intervention trial in congestive heart failure (MERIT-HF). JAMA 2000;283: 1295-302.

4 Susman E. Copernicus: carvedilol heaven-sent in severe heart failure. Inpharma 2000;1255:13-14.

5 Bart BA, Ertl G, Held P, et al. Contemporary management of patients with left ventricular systolic dysfunction: results from the SPICE registry. Eur Heart J 1999;20: $1182-90$.

6 Zannad F. Incidence, clinical and etiologic features, and outcomes of advanced chronic heart failure: the EPICAL study. J Am Coll Cardiol 2000;33:734-42

7 Hall SA, Cigarroa CG, Marcoux L, et al. Time course of improvement in left ventricular function, mass, and geometry in patients with congestive heart failure treated with $\beta$-adrenergic blockade. J Am Coll Cardiol 1995;25: 1154-61.

8 Bristow MR. $\beta$-Adrenergic receptor blockade in chronic heart failure. Circulation 2000;101:558-69.

9 Bowker TJ, Clayton TC, Ingham J, et al. A British Cardiac Society survey of the potential for the secondary prevention of coronary disease: ASPIRE (action on secondary prevention through intervention to reduce events). Heart 1996;75:334-42.

10 Campbell NC, Thain J, Deans HG, et al. Secondary prevention in coronary heart disease: baseline survey of provision in general practice. BM 1998;316:1430-4

11 Senni M, Tribouilloy CM, Rodcheffer R, et al. Congestive heart failure in the community: trends in incidence and survival in a 10-year period. Arch Intern Med 1999;159:29-34.

12 Maggioni AP, Tavazzi L. Introducing new treatments in clinical practice: the Italian approach to beta blockers in heart failure. Heart 1999;81:453-4.

13 Task Force. The task force on heart failure of the European Society of Cardiology. The treatment of heart failure. Eur Heart J 1997; 18:736-53.

14 Packer M. Consensus recommendations for the management of chronic heart failure. Am J Cardiol 1999;83(suppl 2A):2-77A.

15 Opasich C, Tavazzi L, Lucci D, et al. Comparison of one-year outcome in women versus men with chronic congestive heart failure. Am J Cardio 2000;86:353-7.

16 Packer M, Coats AJ, Fowler MB, et al. Effect of carvedilol on survival in severe chronic heart failure. N Engl J Med 2001;344:1651-8.

17 Dargie HJ. Effect of carvedilol on outcome after myocardial infarction in patients with left-ventricular dysfunction: the CAPRICORN randomised trial. Lancet 2001;357:1385-90.

18 Benson K, Hartz AJ. A comparison of observational studies and randomized, controlled trials. N Engl J Med 2000;342:1878-86.

19 Concato J, Shah N, Horwitz RI. Randomized, controlled trials, observational studies, and the hierarchy of research designs. N Engl J Med 2000;342: 1887-92.

20 Pocock SJ, Elbourne DR. Randomized trials or observational tribulations? N Engl J Med 2000;342:1907-9.

21 Abraham WT. Beta-blockers: the new standard of therapy for mild heart failure. Arch Intern Med 2000;160: 1237-47.

22 McMurray JJ. Major beta blocker mortality trials in chronic heart failure: a critical review. Heart 1999;82(suppl 4):14-22.

23 Rochon PA, Tu JV, Anderson GM, et al. Rate of heart failure and 1-year survival for older people receiving low-dose $\beta$-blocker therapy after myocardial infarction. Lancet 2000;356:639-44.

24 Bristow MR, Gilbert EM, Abraham WT, et al. Carvedilol produces dose-related improvements in left ventricular function and survival in subjects with chronic heart failure. MOCHA Investigators. Circulation 1996;94:2807-16

25 Califf RM, O'Connor CM. $\beta$-Blocker therapy for heart failure. The evidence is in, now the work begins. JAMA 2000;283:1335-7.

26 Felch WC. Bridging the gap between research and practice. The role of continuing medical education. JAMA 1997;277:155-6.

27 Del Favero A, Barro G, Vicari G, et al. Health services: an Italian market. Lancet 1996;348:167-75

28 Tognoni G, Fresco C, Maggioni AP, et al. The GISSI story (1983-1996): a comprehensive review. J Intervent Cardiol 1997;10:3-28.

29 Woosley RL. Centers for education and research in therapeutics. Clin Pharmacol Ther 2000;68:109-10.

30 Rawlins $M$. In pursuit of quality: the National Institute for Clinical Excellence. Lancet 1999;353:1079-82. 